HOLLEMAN - WIBERG

ANORGANISCHE CHEMIE 



\title{
LEHRBUCH DER \\ ANORGANISCHEN CHEMIE
}

\author{
Begründet von
}

\section{A. F. HOLLEMAN †}

57. - 70., wesentlich erweiterte, umgearbeitete und verbesserte Auflage

mit einem Anhang Chemiegeschichte und einer Raumbilder-Beilage

sowie 177 Figuren und 29 Struktur-Bildern in stereoskopischer Darstellung

von

PROF. DR. DR.h.c. E G O N WI B ER G

Direktor des Instituts für Anorganische Chemie der Universität München

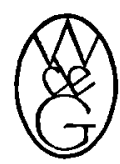

WALTER DE GRUYTER \& CO.

vormals G.J. Göschen'sche Verlagshandlung · J.Guttentag, Verlagsbuchhandlung Georg Reimer - Karl J. Trübner - Veit \& Comp. 
Alle Rechte, auch die des suszugsweisen Nachdrucks, der photomechanischen Wiedergabe, der Herstellung von Mikrofilmen und der Ubersetzung vorbehalten-Copyright 1963 by WALTER DE GRU YTER \& CO., vormals G. J. Goschensche Verlagabandlung - J. Guttentag, Verlagsbuchhandlung - Georg Reimer - Karl J. Trübner - Veit \& Comp. Berlin 30 - Archiv-Nr. 5231631 - Printed in Germany - Satz und Druck: Walter de Gruyter \& Co., Berlin 30 